\title{
Learning from Architects: The Difference between Knowledge Visualization and Information Visualization
}

\author{
Remo A. Burkhard \\ University of St. Gallen \\ Remo.Burkhard@unisg.ch
}

\begin{abstract}
This paper focuses on an aspect which has been neglected, but which is decisive: The transfer of knowledge to different stakeholders; especially the transfer of insights derived from information visualization tools. In knowledge management the transfer of knowledge is a core process, which can be improved by using our innate abilities to process visual representations. The potential of visualizations are manifold. But business managers miss a holistic framework on the use of visualization methods for information exploration and communication tasks. This paper analyzes how architects use visualizations to amplify cognition and to transfer knowledge. It introduces a mediating framework that brings together isolated research directions and defines the new research focus knowledge visualization. Knowledge visualization examines the use of visualizations for the transfer of knowledge between at least two peoples. We found that the new focus is decisive and has implications for researchers in information visualization and knowledge management.
\end{abstract}

Keywords: knowledge visualization, information visualization, knowledge transfer, knowledge management.

\section{Introduction: The Need for Knowledge Visualization}

The transfer of knowledge is a core process and difficult to manage [1]. For the transfer of knowledge the following difficulties need to be solved:

- Information depth: Trade off between an overview and details that need to be communicated.

- Limited time: Limited time, attention and capacity of the recipients.

- Different background: Different cognitive backgrounds and difficulties of decision makers to understand the novel information visualization tools.

- Relevance: Providing the relevant information to different stakeholders.
Today managers only use few visualization types, i.e. PowerPoint presentations, diagrams or clip arts for information exploration and for the transfer of knowledge. Result: The need for information visualization.

The last twenty years various information visualization methods were invented. However it has been neglected to link these methods to the background of managers and to the knowledge management life cycle. As a result managers have difficulties to adapt these new methods. What is missing, is a mediating framework for the use of visualization methods for different tasks that concern managers; starting from information exploration and ending with the transfer of knowledge. The methods should be customized to the recipients' cognitive background and information need. This missing framework would help managers to find the most promising visualization method for the individual task. Result: The need for knowledge visualization.

Knowledge visualization examines methods to reduce the predominant problems of managers:

- Information overload: Decision Makers cannot identify the relevant information.

- Misinterpretation: Decision makers cannot understand, evaluate and interpret the information.

- Misuse: Decision makers cannot use or misuse the information for decision making.

Information visualization scientists can learn from architects: Architects as generalists are experts in the transfer of knowledge between specialists from different fields (engineers, workers, lawyers, customers). In an analysis on the way how architects use visual representation for the transfer of knowledge we found a simple but important insight: Architects combine different visualization types that complement one another to illustrate different levels of details. Combining traditional visualizations with novel information visualizations is a promising approach that increases the knowledge transfer quality (effectiveness, motivation) and the attention of recipients, reduces the information overload and as a consequence improves decision making.

A holistic view and a mediating framework on the use of visualizations for information exploration and for the transfer of knowledge is decisive. Today it is 
missing. Therefore this paper presents an approach for the missing framework that integrates results from the research areas information visualization [2-6], cognitive art [7], communication science [8], information architecture [9] and knowledge management [10].

Further this paper clarifies the difference of the research areas information visualization and knowledge visualization.

The new research focus knowledge visualization and the new framework are promising and have implications for researchers in information visualization, knowledge management and communication studies.

\section{The Potential of Visualizations}

This section presents an overview of visualization research for an understanding of our innate abilities to process visualizations, which can be exploited to improve the transfer of knowledge or insights derived from information visualization tools.

\subsection{General Advantages of Visual Representations}

A majority of our brain's activity deals with processing and analyzing visual images. Images are preattentive and processed before text. In comparison to text, visual images need less energy to be consumed. Alesandrini [11] presents five advantages of abstract images: They are instant, memorable, automatic, global and energizing. Several empirical studies show that visual representations are superior to verbal-sequential representations in different tasks, i.e. to illustrate relations, to identify patterns, to present both an overview and details, to support problem solving and to communicate different knowledge types [12-14].

The use of visual metaphors is effective for the transfer of knowledge [15]. Eppler [16] describes six advantages: (1) to motivate people, (2) to present new perspectives, (3) to increase remembrance, (4) to support the process of learning, (5) to focus the attention of the viewer and (6) to structure and coordinate communication.

\subsection{Visual Cognition and Perception Research}

Miller [17] reports that a human's input channel capacity is greater when visual abilities are used. Our brain has a strong ability to identify patterns, which is examined in Gestalt psychology [18]. Visual imagery $[19,20]$ suggest that visual recall seems to be better than verbal recall. It is not clear how images are stored and recalled, but it is clear that humans have a natural ability to use images. Instructional psychology and media didactics investigate the learning outcomes of text-alone versus text-picture: [21] present different results in knowledge acquisition from text and pictures. Weidenmann [22] explores aspects of illustrations in the learning process. Cognitive neuroscience discusses the underlying cognitive components of picture processing [23].

This section presented an overview on the potential of visualizations and visualization research.

\section{The Difference between Knowledge Visualization and Information Visualization}

This section presents the theoretical background for the definition and distinction of the research areas knowledge visualization and information visualization.

Towards a definition of knowledge: Today there is no consensus on the definition of knowledge. Many writers distinguish between data, information, knowledge and wisdom [24, 25]. But on the distinction between information and knowledge there is no consensus either. Schreyögg [26] presents an overview on this discourse.

Information visualization is a rapidly advancing field of study [2-6]. Card et al. [2] define it, as "... the use of computer-supported, interactive, visual representations of abstract data to amplify cognition".

This definition is well established, and as a result mainly information scientists are engaged in the research community focusing is information exploration. What is missing, is a systematic discourse on the potential of visualizations as a medium for the transfer of knowledge and the integration of non-computer based visualization methods, as architects, artists, designers use them. Because the research area information visualization is well established and clear defined, a new research area with the above focus is necessary. We call this research area knowledge visualization.

We define knowledge visualization as: Knowledge visualization examines the use of visual representations to improve the transfer of knowledge between at least two persons or group of persons.

To illustrate the difference between information visualization and knowledge visualization we refer to Eppler [16] "Apart from facts (to answer questions as what? who? when? how many?) knowledge communication needs to further transfer insights (to answer questions as why? and how?), experiences, attitudes, values, premonitions, perspectives, opinions and predictions, in a way that the recipient can reconstruct similar knowledge, as the sender intended" '. Information visualization and knowledge visualization are both exploiting our innate abilities to effectively process visual representations. But the way of using these abilities differs: Information visualization aims to explore abstract data and to create new insights. Knowledge visualization in contrast aims to improve the transfer of knowledge between at least two persons or groups of persons.

The next section describes how architects use different visual representations to transfer knowledge.

\footnotetext{
${ }^{1}$ Translated by the author
} 


\section{Learning from Architects: The Visualization Type Perspective}

Today happens what Peter Drucker described: "The operating organization tends to become an organization of specialists of all kinds" [27]. Architects are experts in communicating with specialists of different fields. Business professionals and information visualization scientists can learn from architects by adapting their approach to use different visualization types complementary. The five main visualization types they use are: Sketch, Diagram, Image, Object, Interactive Visualization. In the following section we introduce each type:

\subsection{Sketch}

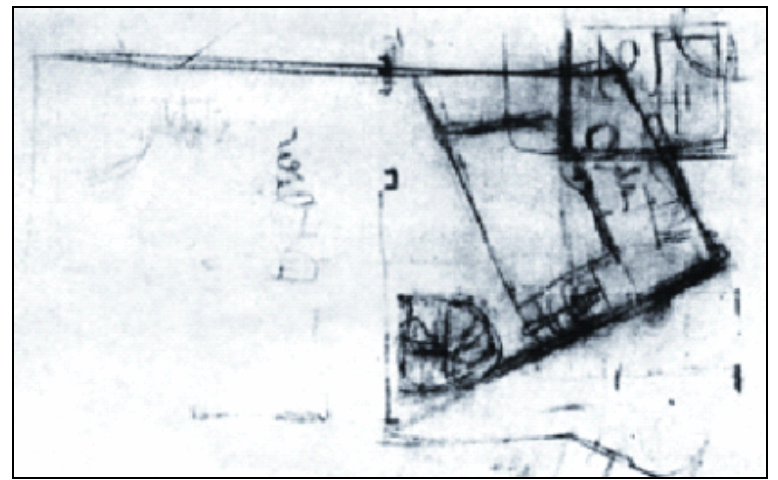

Figure 1: The Sketch by Le Corbusier outlines the concept of a new building. ${ }^{2}$

A sketch is defined as: "Traditionally a rough drawing or painting in which an artist notes down his preliminary ideas for a work that will eventually be realized with greater precision and detail."3

A sketch as seen in Figure 2 outlines a first rough or incomplete draught or plan. It represents the main idea and key features of a preliminary study. Sketches are atmospheric, fast and universally accessible. Sketches help to quickly visualize an idea with the flexibility to handle any shape one imagines.

For the transfer of knowledge in organizations sketches are a versatile and always accessible visualization method, i.e. for meetings or presentations. The use of a pen on a flipchart attracts the attention and supports reasoning and arguing. Sketches allow room for own interpretations and foster creativity.

\subsection{Diagram}

Garland defines a diagram as a "visual language sign having the primary purpose of denoting function and/or relationship" [28].

\footnotetext{
${ }^{2}$ Retrieved August 4, 2003,

http://www.strath.ac.uk/Students/Architecture/ciam/ciam1.html 3 Sketch. Encyclopædia Britannica. Retrieved August 4, 2003, from Encyclopædia Britannica Premium Service. http://www.britannica.com/eb/article?eu=69864
}

Diagrams as seen in Figure 2 are abstract, schematic representations used to explore structural relationships among parts. Unlike maps, diagrams are usually not to scale, nor need to be true to shape. Architects use diagrams to explain concepts and to reduce complexity.

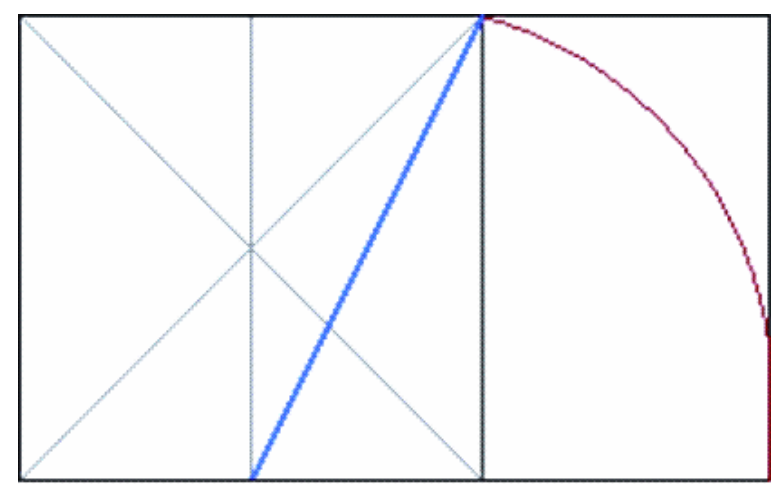

Figure 2: This Diagram represents the construction of the Golden Section.

For the transfer of knowledge in organizations diagrams help to reduce complexity and amplify cognition. Visualizing a complex situation with boxes and arrows, helps in understanding causal relationships. Diagrams help to categorize and structure information to improve decision making. In contrast to sketches they are precise and determined.

\subsection{Image}

Kemp defines an image (Figure 3) as: "Images are representations which are primarily concerned with impression, expression, or realism." [29]. An image can among others be a rendering, a photograph or a painting. Doelker [30] distinguishes different functions of images. They can be "registrative, mimetic, simulative, explicative, diegetic, appellative, decorative, phatic, ontic or energetic" ". Architects can visualize their spatial intuitions through perspectival images.

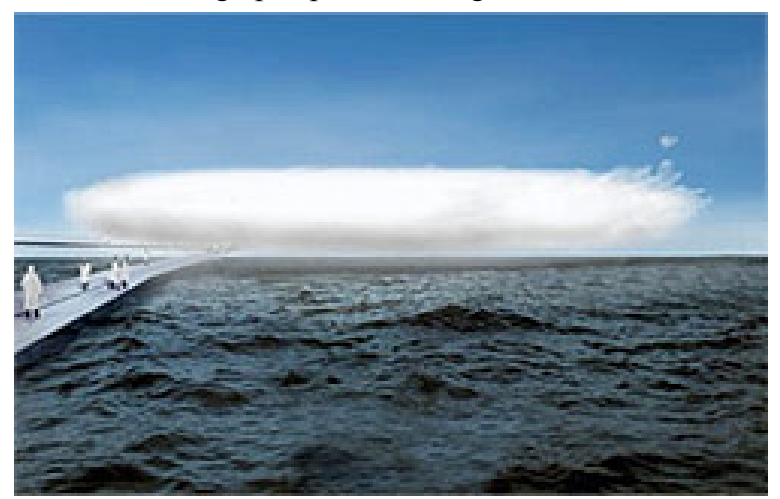

Figure 3: An atmospheric Image of the "blur building" addresses emotions. ${ }^{5}$.

4 Translated by the author.

5 Retrieved August 4, 2003,

http://www.designboom.com/eng/funclub/dillerscofidio.html 
For the transfer of knowledge in organizations images help to get attention, inspire recipients, to anchor a message through addressing emotions, to improve recall or to provoke discussions.

\subsection{Object}

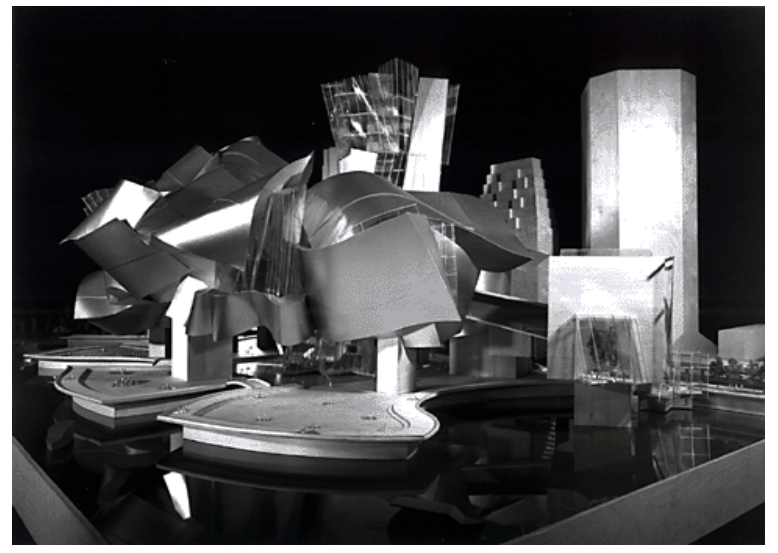

Figure 4: A physical Model by Frank Gehry helps to show relationships among parts. ${ }^{6}$

Physical objects or architectural models bring together plans and sections, help to imagine a spatial composition and enables to see a project from different viewpoints. They can be abstract or realistic. Physical objects are haptic and allow to experience materials. Architectural models allow to control difficult details. In Figure 4 the architectural model helps to imagine and control the design of a very complex building project with curved surfaces.

For the transfer of knowledge in organizations objects help to get the attention, to initiate discussions, present different views, to improve learning through constant presence or to integrate digital interfaces.

\subsection{Interactive Visualization}

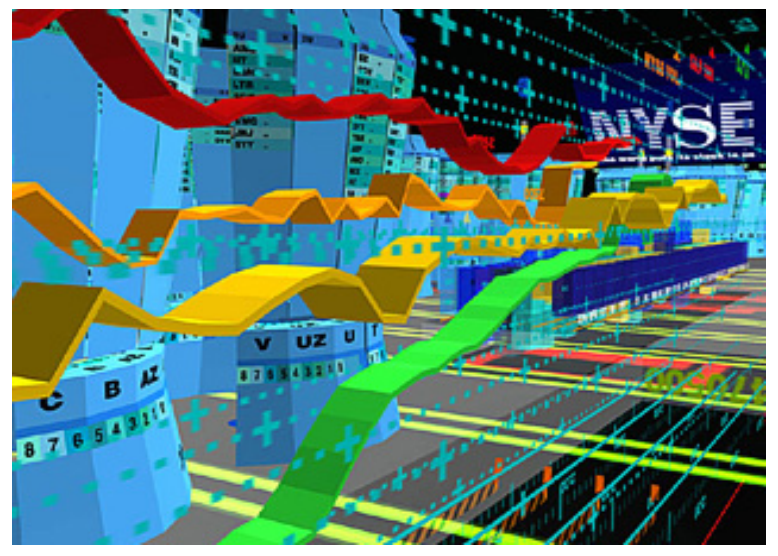

Figure 5: An Interactive Visualization helps to supervise the New York Stock Exchange. ${ }^{7}$

6 Retrieved August 4, 2003,

http://www.thecityreview.com/gehry.html
Interactive visualizations are computer-based electronic visualizations that allows the user to control, combine, and manipulate different types of information or media. Interactive visualizations enable new methods to design, to explore and to communicate. Interactive visualizations offer architects new visualization methods to improve their tasks. Figure 5 illustrates a three dimensional interactive interface that visualizes the data of the New York Stock Exchange. This is an example how architects exploited the potential of new visualization technologies to create new value for the customer.

For the transfer of knowledge in organizations interactive visualizations help for example to fascinate recipients, to enable interactive collaboration, to reveal unforeseen relationships and to present complex data.

This section introduced a visualization type taxonomy, which is deduced from the way architects use different complementary visualization types to transfer knowledge. The next section introduces the yet missing framework that is derived from this taxonomy.

\section{Towards a Framework for Knowledge Visualization}

This section introduces the knowledge visualization framework, which helps (1) to systemize visualization methods, (2) to identify missing research areas and (3) to mediate between different research areas.

\subsection{Classifications of Visual Representations}

Bertin [5] created a semiology of graphic representation methods. Lohse et al. [31] report a structural classification of visual representations. It focuses on the classification of visual representations into hierarchically structured categories. Six groups were introduced: graphs, tables, maps, diagrams, networks and icons. Shneiderman [32] proposes a type by task taxonomy of information visualization where he sorts out the design prototypes to guide researchers to new visualization approaches. Several researchers offer design guidance by discussing examples: [33-36].

\subsection{The Need for a Knowledge Visualization Framework}

A new framework is necessary, because of three reasons:

First, visualization research is not integrated into the context of communication science [8]. The role of the recipient is not studied enough. However in the transfer of knowledge, the recipient plays the major role and needs therefore major attention. Successful visualizations need to be customized to the cognitive background of the recipient so that the recipient can reconstruct own knowledge as intended by the sender.

7 Retrieved August 4, 2003, http://www.asymptote.net 
Second, visualization research is not integrated into knowledge management research [10]. Knowledge management research distinguishes different knowledge types. Today's visualization research focuses primarily on one knowledge type (information, facts).

Third, visualization research needs a genera framework to mediate between the different isolated research areas in the field of knowledge visualization. These are information visualization [2-6, 33, 34], cognitive art [7], knowledge management [10], communication science [8], information architecture [9], learning psychology [21, 22], cognitive psychology [23] or cognitive art [7].

\subsection{The Knowledge Visualization Framework}

For an effective transfer of knowledge three perspectives are important: a Knowledge Type Perspective, a Recipient Type Perspective and a Visualization Type Perspective.

The Knowledge Type Perspective aims to identify the type of knowledge that needs to be transferred. Different types of knowledge are described in knowledge management literature. For our framework we distinguish five types of knowledge: Declarative knowledge (Know-what), procedural knowledge (Knowhow), experimental knowledge (Know-why), orientational knowledge (Know-where), individual knowledge (Know-who). Today no classification exist, that links visualization types and knowledge types.

The Recipient Type Perspective aims to identify the target group and the context of the recipient. The recipient can be an individual, a team, a whole organization or a network of persons. Knowing the context and the cognitive background of the recipient is essential for finding the right visualization method for the transfer of knowledge. Today graphic design and information visualization $[5,33,34]$ do not focus on this perspective.

The Visualization Type Perspective aims to establish a simple taxonomy that is able to structure the existing visualization methods. Today a simple taxonomy that can mediate between different areas (as between planners and decision makers) is missing.

The three perspectives are summarized in Table 1:

\begin{tabular}{lll}
\hline $\begin{array}{l}\text { Knowledge Type } \\
\text { (What?) }\end{array}$ & $\begin{array}{l}\text { Recipient Type } \\
\text { (Whom?) }\end{array}$ & $\begin{array}{l}\text { Visualization } \\
\text { Type (How?) }\end{array}$ \\
\hline Know-what & Individual & Sketch \\
Know-how & Team & Diagram \\
Know-why & Organization & Image \\
Know-where & & Object \\
Know-who & & Interactive - \\
& & Visualization \\
\hline
\end{tabular}

Table 1: Three different perspectives of the knowledge visualization framework

The Knowledge Visualization Framework combines the three perspectives to a three dimensional matrix as seen in Figure 6. As a conceptual framework it helps to structure thinking. In our interactive Knowledge Visualization Cube each visualization method can be linked to one or more suitable coordinates in this framework. Practitioners can use the cube to structure and find the most promising visualization methods by clicking on the slices and individual cubes. Each Knowledge Visualization Cube is context specific and can be filled with different visualizations.

This section presented the missing Framework.

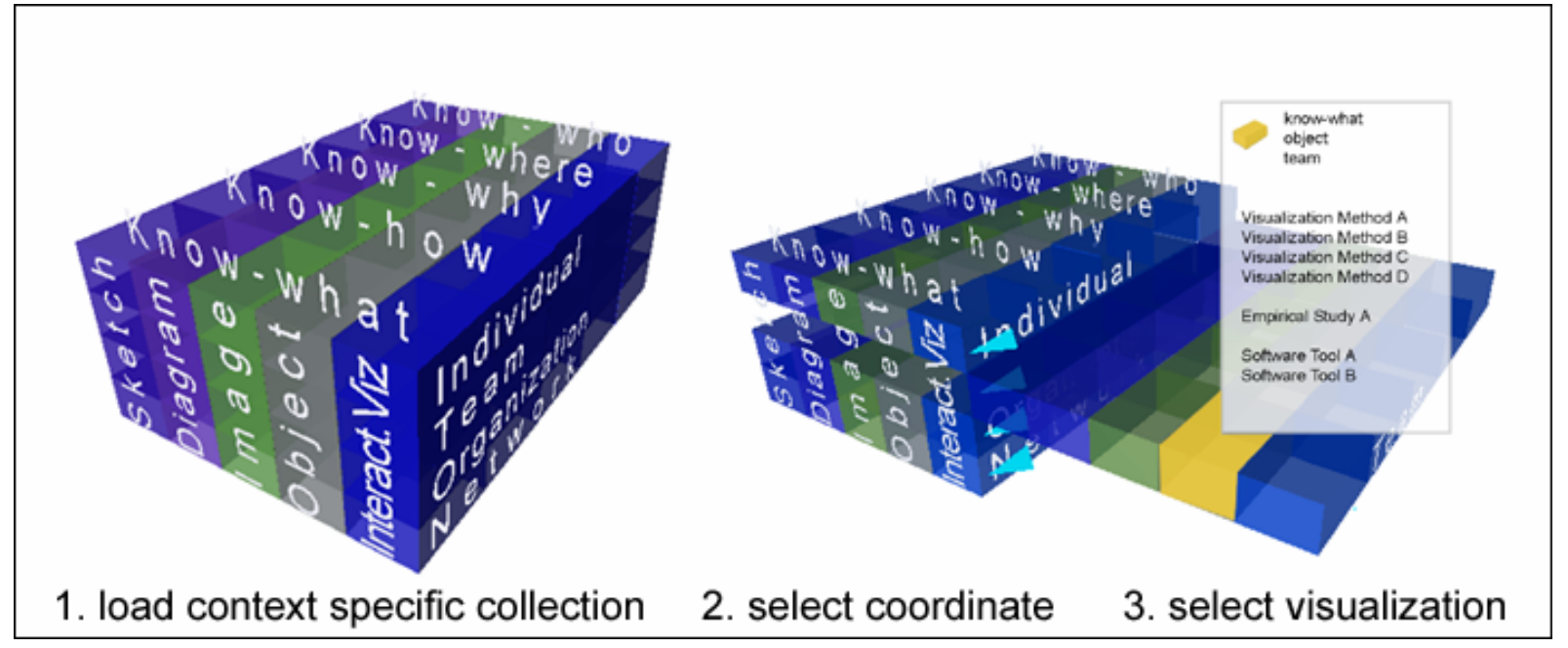

Figure 6. The Knowledge Visualization Cube integrates the three important perspectives to be considered when choosing a visualization method. Slices can be selected which then allow a single cube to be selected. Selecting a link in the appearing view loads detailed information in an additional window. The cube is implemented in VRML. 


\section{Summary}

This paper defined knowledge visualization and explained the difference between the research areas knowledge visualization and information visualization. In contrast to information visualization, which exploits our innate abilities to effectively process visual representation to explore information, knowledge visualization uses these abilities to improve the transfer of knowledge between at least two persons or group of persons. To mediate between different research areas this paper introduced a knowledge visualization framework. This framework aims to systemize research, to identify research gaps and to mediate between researchers from different fields.

The framework is based on three perspectives: A Knowledge Type, a Recipient Type and a Visualization Type Perspective. While the first two taxonomies are established, the visualization type perspective is new. We deduced this taxonomy by analyzing how architects use different complementary visualization types to transfer knowledge. This taxonomy is promising both for researchers and practitioners.

We are currently integrating examples into our framework. We hope that we can identify research gaps and reveal patterns.

\section{References}

[1] G. Probst, S. Raub, et al. Wissen managen, Wie Unternehmen ihre wertvollste Ressource optimal nutzen. Wiesbaden, Gabler/FAZ. 1997.

[2] S. K. Card, J. D. Mackinlay, et al. Readings in Information Visualization; Using Vision to think. Los Altos, CA, Morgan Kaufmann. 1999.

[3] C. Ware. Information Visualization: Perception for Design. San Francisco, Morgan Kaufmann. 2000.

[4] C. Chen. Information Visualisation and Virtual Environments. London, Springer. 1999.

[5] J. Bertin. Graphische Semiologie. Diagramme, Netze, Karten. Berlin, Walter de Gruyter. 1974.

[6] B. Spence. Information Visualization, ACM Press. 2000.

[7] R. Horn. Visual Language: Global Communication for the 21. Century. Brainbridge Island, WA, MacroVU. 1998.

[8] J. Fiske. Communication theory. In Introduction to Communication Studies, John Fiske, Ed. London/New York, Methuen, 1982, pp. 6-24.

[9] R. S. Wurman. Information Architects. Zurich, Graphis Press Corp. 1996.

[10] M. Alavi, D. Leidner. Knowledge Management and Knowledge Management Systems: Conceptual Foundations and Research Issues. In MIS Quarterly, 25 (1), pp. 107-136. 2001.

[11] K. Alesandrini. Survive Information Overload: The 7 best ways to manage your workload by seeing the big picture. Homewood, IL, Business One Irwin. 1992.

[12] J. Larkin, H. Simon. Why a Diagram is (Sometimes) Worth Ten Thousand Words. In Cognitive Science, 11, pp. 65-99. 1987.
[13] A. Glenberg, M. Langston. Comprehension of Illustrated Text: Pictures Help to Build Mental Models. In Journal of Memory and Language, 31 (2), pp. 129-151. 1992.

[14] M. Bauer, P. Johnson-Laird. How diagrams can improve reasoning. In Psychological Science, 4 (6), pp. 372-378. 1993.

[15] I. Nonaka. The Knowledge-Creating Company. In Harvard Business Review, 69 (6), pp. 96-104. 1991.

[16] M. J. Eppler. Visuelle Wissenskommunikation - Der Einsatz von graphischen Metaphern zur Optimierung des Wissenstransfers. In Wissenskommunikation in Organisationen, R. Reinhardt and Martin J. Eppler, Eds., Springer, 2004.

[17] G. A. Miller. The magical number seven, plus or minus two: Some limits on our capacity for processing information. In Psychological Review, 63, pp. 81-97. 1956.

[18] K. Koffka. The Principles of Gestalt Psychology. New York, Harcourt Brace. 1935.

[19] S. M. Kosslyn. Images and Mind. Cambridge, MA, Harvard University Press. 1980.

[20] R. N. Shepard, L. A. Cooper. Mental Images and Their Transformations. Cambridge, MA, MIT Press. 1982.

[21] H. Mandl, J. R. Levin. Knowledge Acquisition from Text and Pictures. Amsterdam, North-Holland. 1989.

[22] B. Weidenmann. When Good Pictures Fail: An Information-Processing Approach to the Effect of Illustrations. In Knowledge Acquisition from Text and Pictures, Heinz Mandl and Joel R. Levin, Eds. Amsterdam, North-Holland, 1989.

[23] M. J. Farah. The cognitive neuroscience of vision. Malden, Massachusetts, Blackwell Publishers. 2000.

[24] V. Allee. The Knowledge Evolution: Expanding Organizational Intelligence. Boston, MA, ButterworthHeinemann. 1997.

[25] J. Rehäuser, H. Krcmar. Wissensmanagement im Unternehmen. In Wissensmanagement, Georg Schreyögg and Peter Conrad, Eds. Berlin, Walter de Gruyter, 1996.

[26] G. Schreyögg. Wenn alles Wissen ist, ist Wissen am Ende nichts?! In $D B W, 63$ (1), pp. 7-22. 2003.

[27] P. F. Drucker. The coming of the New Organization. vol. January-February. 1988

[28] K. Garland. Some General Characteristics Present in Diagrams Denoting Activity, Event and Relationship. In Information Design Journal, 1 (1), pp. 15-22. 1979.

[29] M. Kemp. Visualizations. The Nature Book of Art and Science. Berkeley \& Los Angeles, University of California Press. 2000.

[30] C. Doelker. Ein Bild ist mehr als ein Bild. Visuelle Kompetenz in der Multimedia-Gesellschaft. Stuttgart, Klett-Cotta. 1997.

[31] G. Lohse, K. Biolsi, et al. A Classification of Visual Representations. In Communications of the ACM, 37 (12), pp. 36-49. 1994.

[32] B. Shneiderman. The eyes have it: a task by data type taxonomy for information visualizations. In Proceedings of 1996 IEEE Visual Languages, Boulder (CO), pp. 336343. 1996.

[33] E. Tufte. Envisioning Information. Cheshire, Graphics Press. 1990.

[34] E. Tufte. Visual Explanations. Cheshire, Graphics Press. 1997.

[35] P. Keller, Keller, M. Visual Cues. Practical Data Visualization. Los Alamitos, IEEE Computer Society Press. 1993.

[36] W. J. Bowman. Graphic communication. New York, Wiley. 1968. 